\title{
Aspectos da arborização urbana ecológica
}

A arborização urbana representa a possibilidade de o homem urbano resgatar frações da natureza que foram suprimidas para dentro de seu lar e de seus espaços comunitários. Este trabalho discorre sobre a "arborização urbana ecológica" que, além do plantio exclusivo de árvores nativas regionais e exclusão de espécies exóticas invasoras, se alicerça na biologia floral, fenologia, oferta permanente de alimentos para aves e polinizadores, conservação genética de espécies raras e ameaçadas de extinção e ecologia da paisagem. A arborização urbana ecológica reconhece a biodiversidade nativa como um valor cultural nas áreas urbanas, potencial em processos de conscientização e educação ambiental.

Palavras-chave: Silvicultura Urbana; Invasão Biológica; Conservação da Natureza.

\section{Aspects of ecological urban forestry}

The urban forestry represents a possibility for the urban man to rescue nature fractions that have been removed, and introduce them into their homes and community spaces. This paper discusses about "ecological urban forestry", where we use exclusive native tree species and no alien species, besides it is based on floral biology, phenology, permanent supply of food for birds and pollinators, genetic conservation of rare and endangered species and landscape ecology. The ecological urban forestry recognizes native biodiversity as a cultural value in urban areas as well as a potential value in consciousness and environmental education processes.

Keywords: Urban Forestry; Biological Invasion; Nature Conservation.

\section{Topic: Ecologia e Biodiversidade}

Reviewed anonymously in the process of blind peer
Received: 07/07/2015

Approved: $18 / 11 / 2015$

\section{Fernando Campanhã Bechara}

Universidade Tecnológica Federal do Paraná

http://lattes.cnpq.br/8651851040427432

bechara@utfpr.edu.br

\section{Larissa Regina Topanotti}

Universidade Tecnológica Federal do Paraná

http://lattes.cnpq.br/2165718081828184

laratopanotti@hotmail.com

Lenir Maristela Silva

Universidade Federal do Paraná

http://lattes.cnpq.br/7717334285967201

lenirsilva@ufpr.br

\section{Referencing this:}

BECHARA, F. C.; TOPANOTTI, L. R.; SILVA, L. M.. Aspectos da arborização urbana ecológica. Revista Ibero-Americana de Ciências Ambientais, v.7, n.1, p.49-55, 2016. DOI:

http://doi.org/10.6008/SPC2179-6858.2016.001.0004 


\section{INTRODUÇÃO}

Os ecossistemas urbanos possibilitam uma harmonia entre as condições naturais do meio ambiente e as criadas artificialmente pelo homem (DANSEREAU, 1987). A arborização urbana pode atuar resgatando parte da biodiversidade que foi perdida com a expansão das cidades sobre os ecossistemas naturais. Além disso, ela também pode auxiliar na proteção de recursos hídricos (REIS et al., 2003). Os ecossistemas urbanos, através de sua arborização, considerando aspectos ecológicos como o uso de espécies nativas e que possibilitem a manutenção da fauna regional, podem auxiliar na conservação biológica e genética, mantendo a identidade biológica de cada região (DANTAS e SOUZA, 2004).

Assim, a arborização urbana representa a possibilidade de o homem urbano resgatar frações da natureza que foram suprimidas para dentro de seu lar e de seus espaços comunitários (LEITÃO e AZEVEDO, 1989; SALATINO, 2001). Bairros bem arborizados, avenidas com canteiros, bosques, praças e outras áreas verdes são considerados indicativos de alta qualidade de vida. Contudo, a arborização urbana das cidades brasileiras não demonstra, de modo geral, que essa seja também uma atividade que possa contribuir com melhorias para a conservação da biodiversidade local. Por exemplo, o critério de a espécie ser nativa é extremamente importante para a conservação da biodiversidade, mas ainda não está incorporado à escolha adequada de espécies para a arborização urbana no país (ZILLER et al., 2007; ISERNHAGEN et al., 2009).

Neste sentido, neste trabalho são abordados alguns fundamentos básicos de Biologia da Conservação aplicados à silvicultura urbana com o objetivo de alicerçar os rumos de práticas mais conservacionistas nas cidades, denominadas aqui de "arborização urbana ecológica".

\section{DISCUSSÃO TEÓRICA}

A maior causa de extinção de espécies no globo está associada à supressão de habitats, isto é, ao desmatamento propriamente dito, resultado principalmente da expansão das fronteiras agrícolas, mas também do urbanismo desorganizado. Logo em seguida, o segundo maior agente promotor de extinção está intimamente relacionado com o paisagismo de plantas ornamentais, onde a introdução de espécies exóticas que se tornam invasoras (se apoderam do espaço, água, luz e nutrientes das espécies nativas), resulta no processo denominado internacionalmente como "invasão biológica". Este processo tende a se multiplicar com o passar do tempo, levando ao desequilíbrio ecológico e perdas de biodiversidade das comunidades de entorno à fonte de invasão (SIMBERLOFF, 1999; RICHARDSON et al., 2000; ZILLER, 2000; ESPINDOLA et al., 2003; PYSEK et al., 2004).

Ressalta-se aqui que "espécie exótica" é todo organismo que não é originário do local onde está inserido, desconsiderando-se fronteiras geopolíticas. Neste sentido, uma planta nativa não é "aquela que é do Brasil", como se pensa comumente, e sim, é aquela de ocorrência natural em determinada região geográfica (podendo inclusive apresentar múltiplas nacionalidades). Exemplificando, uma árvore amazônica é considerada como exótica na região sul do país, e vice-versa. 
Vale ressaltar que nem toda espécie exótica é invasora. A espécie africana Delonix regia (Bojer ex Hook) Raf., conhecida como Flamboyant, por exemplo, não pode ser considerada invasora nas regiões do Brasil. Isto porque o Flamboyant não se alastra nem se prolifera, instituindo superpopulações. Essas espécies exóticas que se mantêm contidas nos locais onde foram plantadas não representam ameaça à biodiversidade, podendo em alguns casos serem toleradas na arborização urbana ecológica, quando já estabelecidas (BLUM et al., 2008). Por outro lado, é recomendável incentivar o uso de espécies nativas, e também a implantação de planos de substituição de exóticas, com o objetivo não só de conservação da biodiversidade regional, como também de um resgate cultural local de espécies importantes, que muitas vezes, estão praticamente extintas ou caídas no esquecimento dos idosos ou mesmo no desconhecimento dos jovens. Daí surge a importância do resgate cultural através de questionários aplicados à comunidade idosa e rural, em geral mais conhecedora de possíveis curiosidades e usos acerca das árvores nativas.

Quase a metade das plantas exóticas introduzidas em diferentes países, a maior parte para fins ornamentais, promove invasão biológica de ecossistemas naturais (BINGGELI, 2000). Assim, as poucas comunidades naturais remanescentes em áreas verdes urbanas se tornaram alvo fácil das plantas exóticas invasoras, as quais costumam dominá-las, à curto ou longo prazo. O sucesso competitivo destas plantas alienígenas ("alien plants") é dado, principalmente, pela ausência de predadores naturais para controlar as suas superpopulações e pela ocupação de nichos vagos, que são área restritivas não ocupadas previamente pelas plantas nativas (ZILLER, 2000).

Os EUA contam com uma listagem de espécies invasoras e proibição de sua movimentação sob pena de multas, quarentena de áreas invadidas, programas de controle e impedimento de novas introduções. A Austrália possui programas de prevenção, controle e manejo de invasoras, quarentena de novas plantas antes de serem introduzidas e listagem de plantas com permissão de entrada no país (AUSTRALIA, 2001). Nas diversas regiões do Brasil, há inúmeros exemplos de árvores exóticas invasoras usadas para ornamentação, as quais representam um enorme perigo para a biodiversidade nativa, tais como o Pinheiro-americano (Pinus elliottii Engelm. e P. taeda L. (BECHARA, 2003; BECHARA et al., 2013) e Uva-do-japão (Hovenia dulcis Thunb.) na Região Sul (MAIEVES e RIBANI, 2013), e Ipê-de-jardim (Tecoma stans (L.) ex. Kunth) e Palmeira-australiana (Archontophoenix cunninghamiana H. Wendl. \& Drude) na Região Sudoeste.

Há predomínio de espécies exóticas em praticamente todas as cidades do país (GONÇALVES, 2004; DELESPINASSE et al., 2011). Em Campos do Jordão/SP, por exemplo, mais de 80\% dos indivíduos arbóreos são exóticos (ANDRADE, 2002). Em Campina Grande/PB isso ocorre com mais de 60\% dos indivíduos arbóreos (DANTAS e SOUZA, 2004). Em Pato Branco/PR, em sete bairros analisados, identificou-se uma frequência de 78\% de indivíduos arbóreos exóticos (SILVA et al., 2007; SILVA et al., 2008; CADORIN et al., 2008). Devido ao seu constante uso, muitas das espécies exóticas utilizadas na arborização de cidades são erroneamente consideradas como nativas pela população (BLUM et al., 2008).

Alguns estados brasileiros já divulgaram suas listas oficiais de espécies invasoras, como o Paraná e Santa Catarina. Assim, antes de introduzir uma árvore exótica, deve-se adotar o princípio da precaução, isto é, buscar o histórico desta espécie, verificando se a mesma já apresentou invasão biológica em outros locais 
e se tem potencialidade para tal. Em suma, atualmente tornou-se importante diferenciar três principais grupos funcionais existentes de espécies na arborização urbana ecológica: 1) nativas; 2) exóticas; e 3) exóticas invasoras. O uso do terceiro grupo é aqui proibitivo, pois vai de encontro com o conceito de Conservação da Natureza, proposto neste trabalho.

Na cidade de Maringá- PR, das 87 espécies encontradas nas vias públicas, apenas 24,1\% são nativas do ecossistema Floresta Estacional Semidecidual paranaense regional (nas proximidades de Maringá) enquanto que 75,9\% das espécies eram exóticas desse ecossistema, sendo que, destas, 12 são consideradas invasoras pela Portaria IAP 095/2007 “Lista Oficial de Espécies Exóticas Invasoras para o Estado do Paraná” (BLUM et al., 2008; PARANÁ, 2007).

Em trabalho desenvolvido por Biondi e Muller (2013), em cinco parques urbanos de Curitiba-PR, foram identificadas 149 espécies, sendo 56 nativas da região de Curitiba, 38 nativas de outras regiões do Brasil, 37 exóticas e 18 identificadas até o gênero. Das 37 espécies exóticas, 13 espécies são exóticas invasoras, segundo a portaria IAP $n^{\circ}$ 095/2007 (PARANÁ, 2007) e o Decreto $n^{\circ} 473 / 2008$ da Prefeitura Municipal de Curitiba (CURITIBA, 2008).

Variações genotípicas entre populações de uma espécie podem ser observadas mesmo dentro de uma formação fitogeográfica, devido às adaptações de cada espécie ao longo das gerações. É importante lembrar que algumas espécies podem apresentar maior plasticidade e adaptabilidade, ocorrendo em vários ecossistemas, demonstrando um potencial interessante para utilização em arborização urbana. Ao se utilizarem espécies nativas regionais na arborização de cidades, a coexistência e sobrevivência dessas espécies, no local, são mais garantidas (ISERNHAGEN et al., 2009).

Assim, tornou-se fundamental que as exóticas invasoras sejam, gradativamente e de forma planejada, substituídas por outras espécies nativas da região fitoecológica local para a arborização de vias públicas. Da mesma forma, é necessário que haja uma conscientização da população e dos técnicos responsáveis pela arborização sobre a problemática destas espécies exóticas invasoras, evitando que ocorram novas introduções que possam mais tarde acarretar invasão biológica (BIONDI e MACEDO, 2008; BLUM et al., 2008).

O uso de espécies nativas gera ganhos ambientais, estéticos e culturais para o ambiente urbano (MACHADO et al., 2006). Segundo Sampaio (2006), quanto maior o número de espécies nativas melhor para a biodiversidade do local, para melhoria da regeneração natural nas florestas urbanas e para o cruzamento de espécies encontradas na cidade tanto nas vias públicas como nos parques e jardins.

Outros parâmetros podem ser considerados para embasar o uso de espécies nativas regionais, como a proximidade de remanescentes florestais de vegetação nativa e a formação de corredores ecológicos, para atração da avifauna (ISERNHAGEN et al., 2009). Além do uso de diversidade florística que pode e deve ser buscada nos fragmentos florestais mais próximos da área do projeto paisagístico, a arborização urbana ecológica deve estar preocupada com a fenologia da comunidade de árvores urbanas implantadas. Assim, deve-se fornecer um padrão sequencial de floração e frutificação, as quais compõem os alimentos principais (pólen, néctar e frutos carnosos ou com arilo comestível) para a atração e manutenção de fauna silvestre na 
zona urbana. Desta maneira, seja em uma cidade (maior escala) ou em uma avenida (menor escala), devem ser fornecidos flores e frutos ao longo de todos os meses do ano, sem deixar lacunas com períodos sem alimento para as aves e polinizadores (REIS et al., 2003). Sugere-se incrementar o uso de espécies com floração ou frutificação longa nas cidades, de modo a garantir recursos para a fauna local e também circunvizinha (AGOSTINI e SAZIMA, 2003). Tais espécies poderiam desempenhar o papel das "espécieschave" (GILBERT, 1980) no contexto urbano, tornando-se importantes fontes de recursos para aves, borboletas, etc. em períodos do ano com baixa disponibilidade de alimentos.

Outra ferramenta ecológica potencial para o paisagismo urbano é a biologia floral. Por exemplo, os beija-flores são especialmente atraídos por flores vermelhas, em forma de tubo e preferencialmente dispostas de "boca" para baixo ou na horizontal, onde eles conseguem sugar o néctar pairando no ar. Borboletas são atraídas por flores com longos tubos e grandes pétalas coloridas formando uma superfície ampla para o seu pouso (REIS et al., 2003). Estes animais, além de belos e harmoniosos no espaço urbano, possibilitam a polinização, evento biológico responsável pela conservação genética. As aves em geral desempenham papel fundamental na ecologia das cidades, haja vista que contribuem também para o controle de pragas, e dispersão de sementes, além de tornar o ambiente mais bonito com seus cantos e plumagens (PEREIRA et al., 2005).

A arborização urbana ecológica também pode auxiliar na conservação genética de espécies raras e ameaçadas de extinção. Para isso, é importante quebrar o paradigma de árvores urbanas produzidas com sementes coletadas de uma única matriz (baixa variabilidade genética). É preciso orientar os coletores de sementes e produtores de mudas para arborização para que busquem o maior número de matrizes possíveis, trazendo uma maior variabilidade genética para o ecossistema urbano, através de sementes de origem conhecida e coletadas de modo planejado, como por exemplo, em pomares específicos para a produção de sementes (REIS e WIESBAUER, 2006).

Finalmente, considera-se que as florestas urbanas, pequenos fragmentos de vegetação nativa existentes em parques e nas malhas urbanas de grandes cidades, podem, em muitos casos, abrigar considerável riqueza de espécies. Por outro lado, encontram-se comumente isolados na paisagem, sem nenhuma garantia de que as espécies nativas e as funções e interações ecológicas do ecossistema permanecerão em condições necessárias para sua manutenção genética. Daí a importância de formar conexões de vegetação nativa por meio da arborização urbana, seja via corredores (geralmente em zonas ciliares) quando possível, ou até mesmo com a arborização estratégica de ruas avenidas, onde os indivíduos arbóreos podem atuar como "trampolins ecológicos" (stepping stones) facilitando a passagem da fauna de árvore em árvore direcionando-a até às áreas verdes e floresta urbanas (BAUM et al., 2004; ZILLER et al., 2007; ISERHAGEN et al., 2009). A importância da formação de corredores ecológicos no ambiente urbano é abordada por Pennignton et al. (2008), onde os autores perceberam que as aves foram positivamente associadas a áreas com cobertura de árvores e as aves migratórias preferiram áreas verdes maiores, sobretudo as matas ciliares. Eles também constataram que as aves migratórias em trânsito optam por árvores nativas e maduras, onde podem encontrar alimento. 
O ambiente urbano, mesmo se tornando atrativo para a fauna regional, nunca será igual ao ecossistema original. Nesse sentido, políticas de implantação de arborização urbana, com base nas espécies nativas regionais, devem ser planejadas de modo a promover a conservação da natureza em escala regional, permitindo a existência de mosaicos e uma permeabilidade urbana que permita a sobrevivência da biota regional e o bem-estar das populações humanas (ISERNHAGEN et al., 2009).

\section{CONSIDERAÇÕES FINAIS}

Dentro do atual contexto mundial sobre os efeitos da invasão biológica, tornou-se necessário divulgar a problemática das espécies exóticas invasoras usadas na arborização urbana no Brasil, assim como a adoção de práticas de precaução, controle e erradicação, além da restauração de áreas verdes e florestas urbanas invadidas. Disponibilizar recursos para melhorias na permeabilidade da matriz urbana pode constituir uma forma de conservação de espécies nativas, incluindo raras e ameaçadas de extinção. Finalmente, a "arborização urbana ecológica" reconhece a biodiversidade nativa como um valor cultural dentro do meio urbano, potencial para processos de conscientização e educação ambiental.

\section{REFERÊNCIAS}

AGOSTINI, K.; SAZIMA, M.. Plantas ornamentais e seus recursos para abelhas no Campus da Universidade Estadual de Campinas, estado de São Paulo, Brasil. Bragantia, Campinas, v. 62, n. 3, p. 335-343, 2003.

ANDRADE, T. O.. Inventário e análise da arborização viária da estância turística de Campos de Jordão, SP. São Paulo/SP. Dissertação (Mestrado em Agronomia) - Escola Superior de Agricultura "Luiz de Queiroz", Universidade de São Paulo - Piracicaba, SP, 2002.

AUSTRALIA. Coastal dune management: a manual of coastal dune management and rehabilitation techniques. New South Wales, Department of Land and Water Conservation, p.73-78, 2001.

BAUM, K. A.; HAYNES, K. J.; DILLEMUTH, F. T. P.; CRONIN, J. $T$.. The matrix enhances the effectiveness of corridors and stepping stones. Ecology, Ithaca, v. 85, n. 10, p. 2671-2676, 2004.

BECHARA, F. C.. Restauração ecológica de restingas contaminadas por Pinus no Parque Florestal do Rio Vermelho, Florianópolis, SC. Dissertação (Mestrado em Biologia Vegetal), Universidade Federal de Santa Catarina Florianópolis, SC, 2003.

BECHARA, F. C.; REIS, A.; BOURSCHEID, K.; VIEIRA, N. K.; TRENTIN, B. E.. Reproductive biology and early establishment of Pinus elliottii var. elliottii in Brazilian sandy coastal plain vegetation: implications for biological invasion. Scientia Agricola, Piracicaba, v.70, n.2, p.88-92, 2013.

BINGGELI, P. The human dimension of invasive woody plants. 2008.
BIONDI, D.; MACEDO, J. H. P.. Plantas invasoras encontradas na área urbana de Curitiba (PR). Floresta, Curitiba, v.38, n.1, p.129-144, 2008.

BIONDI, D.; MULLER, E.. Espécies arbóreas invasoras no paisagismo dos parques urbanos de Curitiba, PR. Floresta, Curitiba, v.43, n.1, p.69-82, 2013.

BLUM, C. T.; BORGO, M.; SAMPAIO, A. C. F. Espécies exóticas invasoras na arborização de vias públicas de Maringá-PR. Revista da Sociedade Brasileira de Arborização Urbana, Piracicaba, v.3, n.2, p.78-97, 2008.

CADORIN, D. A.; SILVA, L. M.; HASSE, I.; BETT, C. F.; EMER, A. A.; OLIVEIRA, J. R.. Características da arborização dos bairros Cadorin, Parzianello e La Salle em Pato Branco PR/2007. Revista da Sociedade Brasileira de Arborização Urbana, Piracicaba, v.3, n.4, p.40-52, 2008.

CURITIBA. Decreto no 473/2008, de 10 de junho de 2008. Define as espécies florestais consideradas como exóticas invasoras para o município de Curitiba e dá outras providências. Curitiba, 5 jun. 2008.

DANSEREAU, P.. Les dimensions écologiques de espace urbain. Cahiers de géographie du Quebéc, Quebec, v.31, n.84, p.333-395, 1987.

DANTAS, I. C.; SOUZA, C. M. C.. Arborização urbana na cidade de Campina Grande - PB: inventário e suas espécies. Revista de Biologia e Ciências da Terra, Campina Grande, v.4, n.2, 2004.

DELESPINASSE, C. F. B.; HASSE, I.; SILVA, L. M.; CAMPESTRINI, F.. Cenário da arborização urbana nas maiores cidades do 
Estado do Paraná. Revista da Sociedade Brasileira de Arborização Urbana, Piracicaba v.6, n.3, p.149-171, 2011.

ESPÍNDOLA, M. B., BECHARA, F. C., BAZZO, M. S. Recuperação ambiental e contaminação biológica: aspectos ecológicos e legais. Biotemas, Florianópolis, v.18, p.27-38, 2005.

GILBERT, L. E. Food web organization and the conservation of neotropical diversity. In: SOULE, M. E.; WILCOX, B. A. Conservation Biology: an evolutionary-ecological perspective, p.11-33, 1980.

GONÇALVES, W.. Árvores para o ambiente urbano. Viçosa, Aprenda Fácil, 2004.

ISERNHAGEN, I.; LE BOURLEGAT, J. M. G.; CARBONI, M.. Trazendo a riqueza arbórea regional para dentro das cidades: possibilidades, limitações e benefícios. Revista da Sociedade Brasileira de Arborização Urbana, Piracicaba, v.4, n.2, p.117-138, 2009

LEITAO, H. F.; AZEVEDO, D.. Critérios gerais para a implantação de um parque ecológico. Campinas, UNICAMP, 1989.

MACHADO, R. R. B.; MEUNIER, I. M. J.; SILVA, J. A. A.; CASTRO, A. A. J. F.. Árvores nativas para a arborização de Teresina, Piauí. Revista da Sociedade Brasileira de Arborização Urbana, Piracicaba, v.1, n. 1, p. 10-18, 2006.

MAIEVES, H. A.; RIBANI, R. H.. Reconhecimento de exemplares de Hovenia dulcis Thunberg, na arborização urbana de Curitiba-PR. Revista da Sociedade Brasileira de Arborização Urbana, Piracicaba, v.8, n. 1, p. 17-26, 2013.

PARANÁ. Instituto Ambiental do Paraná. Portaria IAP n 095, de 22 de maio de 2007. Reconhece a Lista Oficial de Espécies Exóticas Invasoras para o estado do Paraná, estabelece normas de controle e dá outras providências. Curitiba, 22 maio 2007.

PENNINGTON, D. N.; HANSEL, J.; BLAIR, R. B.. The conservation value of urban riparian areas for landbirds during spring migration: land cover, scale, and vegetation effects. Biological Conservation, New York, v.141, n. 5, p.1235-1248, 2008.

PEREIRA, G. A.; MONTEIRO, C. S.; CAMPELO, M. A.; MEDEIROS, C.. O uso de espécies vegetais, como instrumento de biodiversidade da avifauna silvestre, na arborização pública: o caso do Recife. Atualidades Ornitológicas, Ivaiporã, n. 125, p. 1-15, 2005.

PYŠEK, P.; RICHARDSON, D. M.; REJMÁNEK, M.; WEBSTER, G. L.; WILLIAMSON, M.; KIRSCHNER, J.. Alien plants in checklists and floras: towards better communication between taxonomists and ecologists. Taxon, Bratislava, v.53, n.1, p.131-43, 2004

REIS, A., ANJOS, A., LESSA, A. P., BECHARA, F. C.. Critérios para a seleção de espécies na arborização urbana ecológica. Sellowia, Itajaí, v.53-55, p.51-67, 2003.

REIS, A.; WIESBAUER, M. B.. O uso de sementes na restauração ambiental. In: HIGA, A. R.; SILVA, L. D. (Eds.). Pomar de sementes de espécies florestais nativas. Curitiba. FUPEF, p. 83-92, 2006.

RICHARDSON, D.M.; PYSEK, P.; REJMÁNEK, M.; BARBOUR, M. G.; PANETTA, D.; WEST, C. J. Naturalization and invasion of alien plants: concepts and definitions. Diversity and Distributions, Malden, v.6, p.93-107, 2000.

RODRIGUES, L. S.; COPATTI, C. E.. Diversidade arbórea das escolas da área urbana de São Vicente do Sul/RS.

Biodiversidade Pampeana, Uruguaiana, v.7, n.1, p.7-12, 2009.

SALATINO, A.. Nós e as plantas: ontem e hoje. Revista Brasileira de Botânica, São Paulo, v.24, n.4, p.483-490, 2001.

SAMPAIO, A. C. F.. Análise da arborização de vias públicas das principais zonas do plano piloto de Maringá-PR. Dissertação (Mestrado em Geografia), Universidade Estadual de Maringá - Maringá, PR, 2006.

SILVA, L. M.; HASSE, I.; MOCCELLIN, R.; ZBORALSKI, A. R. Arborização de vias públicas e a utilização de espécies exóticas: o caso do bairro centro de Pato Branco/PR. Scientia Agraria, Curitiba, v.8, n.1, p.47-53, 2007.

SILVA, L. M.; RODIGHIERO, D. A.; HASSE, I.; CADORIN, D. A.. Arborização dos bairros Pinheiros, Brasília e Bancários em Pato Branco/PR. Scientia Agraria, Curitiba, v.9, n.3, p.275282, 2008.

SIMBERLOFF, D.. Nonindigenous species: a global threat to biodiversity and stability In: RAVEN, P; WILLIAMS, T. (Eds.). Nature and Human Society: the quest for a sustainable world. National Academy Press, Washington, p.325-334, 1999.

ZILLER, S. R.. A estepe gramíneo-lenhosa no segundo planalto do Paraná: diagnóstico ambiental com enfoque à contaminação biológica. Tese (Doutorado em Engenharia Florestal). Universidade Federal do Paraná, Curitiba, 2000.

ZILLER, S. R.. Plantas Exóticas Invasoras: a ameaça da contaminação biológica. Revista Ciência Hoje, v.20, n.178, p.77-79, 2001

ZILLER, S. R.; ZENNI, R. D.; DECHOUM, M. S.. Espécies exóticas invasoras na arborização urbana: problemas e soluções. In: XI CONGRESSO BRASILEIRO DE ARBORIZAÇÃO URBANA. Anais. Vitória: SBAU, 2007. 